\title{
COCHLEAR IMPLANT: INDICATIONS, CONTRAINDICATIONS AND COMPLICATIONS
}

\author{
Oguz Kadir Egilmez ${ }^{1}$, M. Tayyar Kalcioglu ${ }^{2}$ \\ ${ }^{1}$ Malkara State Hospital, ENT Clinic, Tekirdă̆, Turkey \\ ${ }^{2}$ Istanbul Medeniyet University, Faculty of Medicine, Department of Otorhinolaryngology, \\ Istanbul, Turkey
}

\begin{abstract}
Cochlear implant (CI) is a surgically implanted electronic device that provides a sense of sound to a person who is profoundly deaf. CI represents the current treatment for patients affected by profound sensorineural hearing loss (SNHL). At first times, only deaf adults were considered to be candidates for a CI; however, with the development of technology and gained experience by pshycians, indications for cochlear implantation have been expanded. Today, CIs are implanted also in children and broader indications are followed. There are, however, a number of patients who are potential candidates for CI but do not completely fulfill the current indications. Residual hearing and duration of deafness represent prognostic indicators for CI performance; however, prelingually deafened adults and children with residual hearing are still point at issue. Anatomical variations such as cochlear malformation, ossification and chronic otitis media still represent a contraindication to $\mathrm{CI}$ for some surgeons. Although the technology for cochlear implant surgery is advancing everyday, there may be several complications related to the device or operation and some of them can be healed only with medical therapy but some are serious enough to process to reimplantation. In this article the indications and contraindications for cochlear implant candidates and complications that may occur during or after the operation were reviewed under the light of the literature.
\end{abstract}

Keywords: Cochlear implant, indication, contraindication, complication, reimplantation

\section{INTRODUCTION}

Hearing loss is one of the most common health problems. Approximately 1-3 out of 1000 babies is born with a hearing loss (1). Lack of acoustic stimuli to the auditory system arising from sensorineural hearing loss has been usually coped with the inception of cochlear implantation in the 1980s (2). Cochlear implants (CI) can improve speech and sound

Address for correspondence:

Mahmut Kalcioglu, M.D., Professor

Istanbul Medeniyet University, Faculty of Medicine,

Department of Otorhinolaryngology,

Goztepe Training and Research Hospital,

34722, Istanbul, Turkey

e-mail: mtkalcioglu@hotmail.com

Mobile: +902165709074

Received: November 4, 2015

Accepted: December 1, 2015 perception, promote development of verbal language and auditory skills and educational development and also suppress tinnitus in some patients (2). Depending on the grade of hearing loss, affected individuals can be fitted successfully with hearing aids. For patients with hearing loss that is not relieved with hearing aids, a cochlear implant may present an opportunity for hearing.

The CI is a device which is surgically placed into the cochlea and converts sound to an electrical signal. This signal is conducted via electrodes to the spiral ganglion cells in the cochlea. As of 2012, an estimated 324,000 patients worldwide have CIs implanted (3). But, this number represents only a small number of individuals potentially benefitted from implantation.

Although individual reactions to CIs depend on a number of psychosocial and physical factors, the new trend for improving performance with more 
sophisticated hardware i.e. electrodes and programming strategies has loosened the indications for cochlear implantation in recent years (3). Plenty of devices are approved recently for use in patients with unilateral hearing loss rather then a bilateral profound loss that was required prevoiusly (2). Additionally, some studies have begun using shorter electrode arrays for shallow insertion in patients with substantial low-frequency residual hearing. This technique will allow the recipient to continue to use amplified hearing aid for the low frequencies simultaneously with a CI for the high frequencies.

Complications are unavoidable with cochlear implantation as with all surgical procedures. They may be easy to treat like temporary vertigo or terrible enough like death due to meningitis. It is advisable that surgeons without prior experience should not perform an operation themselves; they should work with a more experienced surgeon when performing their first implant.

In this article, indications and related etiologic factors, contraindications and complications of cochlear implantatation were discussed according to the literature.

\section{INDICATIONS OF COCHLEAR IMPLANTATION}

From the first introduction of this device, FDA which has great influence on cochlear implantation candidacy has pursued several clinical trials on this issue. Many supplements about the technological improvements of the devices have been presented to the FDA. Therefore, implant candidacy is generally based on the best knowledge and the decision of the surgeon following the patient (2). Patients, child or adult, with severe-to-profound bilateral sensorineural hearing loss and some pathologies limited to the cochleae are potential applicants for cochlear implantation. There are some classical criteria for candidacy but changes have firstly included implanting patients with increasing degree of preoperative open-set speech skills, patients with increasing degree of residual hearing, patients, especially children at younger ages and with abnormal cochlea as much as possible (2).

The most widely used criteria for candidacy include bilateral severe-to-profound sensorineural hearing loss (SNHL), the optimal age should be between 12 months and 5 years but younger ages can also be the candidate, lack of improvement in hearing and speech benefits from hearing aids after a 3 months usage, the family of the patient will promote the surgery and postoperative rehabilitation, the family and the patients have convenient hope for the outcome of the surgery and are available for rehabilitation and education and also there should be no contraindications for surgery (4). If the audimetric candidacy is described distinctly, it ranges from severe to profound SNHL for ages from 2 to 17 years and profound SNHL for ages from 12 to 24 months, that is for children aged 12-24 months, the pure-tone average (PTA) should equal or exceed $90 \mathrm{~dB}$ (3). For patients older than 24 months, the PTA should equal or exceed $70 \mathrm{~dB}$. If the patient can detect speech with best-fit hearing aids, a speech-recognition test in a sound field of $55 \mathrm{~dB}$ HL sound pressure level (SPL) is performed (3). A number of speech recognition tests are currently in use. Speech recognition criteria include limited benefit from binaural amplification trial with word recognition tests like MLNT (Multisyllabic Lexical Neighborhood Test) and LNT (Lexical Neighborhood Test) scores $\leq 30 \%$ for $2-17$ years and limited benefit from binaural amplification trial for 12-24 months $(2,3)$ (Table 1$)$.

If the prelingual patient is at younger age when the implantation is performed, the outcome will be better. As a result, the patient will make full usage of the brain, auditory deprivation can be prevented, and speech and language abilities can be developed easily because the brain cannot lose its plasticity. Before implantation, children bigger than 6 years of age and adolescents should wear fitted hearing aids and have some auditory practice. Also they should be given language training while they are young (4).

For postlingual patients, some additional criteria can be as postlingual deafness of all ages, no or little benefit from hearing aid amplification with preoperative scores for speech recognition test is lower than $50 \%$ in ear to be implanted and $60 \%$ bilaterally in best-aided condition $(2,4)$. Also, emotional and psychological stability with good motivation is important for candidacy. The language environment of the home and workplace after surgery affect the outcome. Another affecting factor for the outcome is the onset age and duration of hearing loss. Generally, an early onset and a long duration of hearing loss have poorer outcomes for postlingual patients $(4,5)$. 
Oguz Kadir Egilmez, M. Tayyar Kalcioglu

Table 1. Indications for patients related with cochlear implant candidacy (SNHL - sensorineural hearing loss, PTA pure-tone average)

Indications of the Cochlear Implantation

Audimetric candidacy

\section{$12-24$ months}

Profound SNHL - PTA $\geq 90 \mathrm{~dB}$

Speech recognition tests

\section{2-24 months}

Limited benefit from binaural amplification

Prelingual SNHL

Perlingual SNHL

Postlingual SNHL

New concepts in indications

\section{2-17 years}

Severe to profound SNHL- PTA $\geq 70$ $\mathrm{dB}$

\section{2-17 years}

Limited benefit from binaural amplification with scores $\leq 30 \%$
$>18$ years

Severe to profound SNHL- PTA $\geq 70 \mathrm{~dB}$

Younger age, Hearing preservation, Unilateral deafness, Tinnitus, Bilateral implantation

In addition to these criterias, the indications have been loosened for candidacy because of some reasons mentioned above e.g. technological developments or influences by some health agencies. New concepts in the candidacy are dealing with the following topics; $\mathrm{CI}$ and hearing preservation, cochlear implantation at younger ages, $\mathrm{CI}$ and relation with genetic hearing loss, CI for unilateral deafness and tinnitus, CI and neural plasticity and bilateral cochlear implantation $(2,5)$. In the ongoing part of the article, some etiologic factors resulting in hearing loss related with the candidacy of cochlear implantation will be discussed.

\section{ETIOLOGIES OF HEARING LOSS AND CANDIDATES FOR COCHLEAR IMPLANTATION: \\ A-Prelingual Causes \\ Genetic}

Hereditary hearing loss accounts for almost $50 \%$ of all congenital sensorineural hearing loss, and it is caused by genetic mutations. It can be the result of a mutation in a single gene, or combination of mutations of different genes (6). Herediter hearing loss can either be non-syndromic, which is restricted to the inner ear, or syndromic and a part of multiple anomalies affecting the body. Non-syndromic HL can further be categorised by its mode of in- heritance (6). Approximately $20 \%$ of non-syndromic sensorineural hearing loss (NSSHL) is inherited as autosomal dominant, which is also referred to as DFNA; this type of hearing loss is usually delayed onset. Eighty percent of inherited HL is autosomal recessive (DFNB), in which hearing loss is generally congenital, but some forms may emerge later in life. The inheritance of the remaining types of $\mathrm{HL}$ is either mitochondrial or X-linked (DFN) (less than 1 percent). To date, 125 deafness loci have been reported in the literature; 58 DFNA loci, 63 DFNB loci and $4 \mathrm{X}$-linked loci (7).

The GJB2 gene encodes for the protein Connexin 26 (Cx26) and the most common cause of nonsyndromic autosomal recessive deafness is mutation in Cx26, which is responsible for approximately $20 \%$ of hereditary hearing loss in children (8). Connexins are transmembrane proteins forming gap-junction channels which allow cell-to-cell communication and ion transport. Some examples of syndromic hearing loss are Waardenburg, Stickler, Brachio-oto-renal, Treacher Collins, Neurofibromatosis, Usher, Jervell Lange-Neilsen, Alport, and Pendred syndromes (8).

\section{Infectious}

About the nonmeningitis causes, the most common environmental cause of hearing impairment in children is congenital Cytomegalovirus (CMV) (9). Twenty five to thirty three percent of childhood deaf- 
ness can be generated by non-genetic or environmental causes. Asymptomatic congenital CMV infections can be a cause of mild to profound sensorineural hearing loss in $10-15 \%$ of patients (9). Rubella, toxoplasmosis, syphilis, measles and mumps are some of the other potential infectious agents causing hearing loss.

\section{Auditory neuropathy/dyssynchrony}

Auditory neuropathy is a kind of hearing loss in which the outer hair cells are present and functional, but sound can not be transmitted truly to the auditory nerve and brain. It is also known as auditory neuropathy/auditory dyssynchrony or auditory neuropathy spectrum disorder and implicates the vestibulocochlear nerve as the site of pathology (10). Otoacoustic emissions, the cochlear microphonic of electrocochleography or pure-tone audiometry can be used to assess outer hair cell function. A defect in spiral ganglion cells, inner hair cells or the synapse between the two can be the cause of this disorder (10).

Auditory neuropathy is seen in both children and adults. Normal to profound hearing loss can be obtained on pure-tone audiometry, but especially speech discrimination testing with poor performance is the common criteria in patients with auditory neuropathy (10). The most potent risk factors are anoxia, hyperbilirubinemia, and prematurity for auditory neuropathy spectrum. In several studies it was reported that patients had some forms of hereditary nonsyndromic autosomal dominant auditory neuropathy progressing to outer hair cell malfunction causing decline in pure-tone audiometer results. Some of the patients in these series benefitted from hearing aids or FM devices but in some a CI is the only way to communicate (10-12).

\section{Hyperbilirubinemia}

In the neonatal jaundice, bilirubin may pass the blood-brain barrier and be deposited in the ventral cochlear nucleus and can cause sensorineural hearing loss. On the ABR test, transient loss of wave IV and $\mathrm{V}$ is seen in 1 to 3 of newborns with bilirubin levels of $15-25 \mathrm{mg} / \mathrm{dL}$. Higher concentrations of bilirubin in the blood are also a risk factor for auditory neuropathy (13).

\section{B-Perlingual and/or Postlingual Causes}

\section{Infectious}

One of the infectious causes for hearing loss is meningitis. The most common organisms causing meningitis include Haemophilus influenzae, Streptococcus pneumoniae and Neisseria meningitidis. Approximately $9 \%$ of childhood deafness can be caused by meningitis (14). The highest incidence of organisms that cause hearing loss has $S$. pneumoniae with $31 \%$ (14). If $S$. pneumoniae is the causative organism for hearing loss, patients are developing obstruction of the cochlear lumen ie labyrinthitis ossificans and it makes CI surgery difficult $(14,15)$.

\section{Ototoxicity}

Plenty of medications can cause hearing loss and the most well known ototoxic medication are aminoglycoside antibiotics (16). Other commonly known ototoxic medications include salicylates, loop diuretics, erythromycin, vancomycin, quinine and cisplatin. Because of severe to profound sensorineural hearing loss after ototoxicity, CI is a good treatment option.

\section{Trauma}

After temporal bone trauma, conductive hearing loss most commonly happens because of tympanic membrane perforation, ossicular displacement or hemotympanum. The otic capsule is more resistant to trauma but sometimes breaks may involve the labyrinth or/and cochlea. If a fracture passes from the otic capsule, it almost always results in severe-to-profound sensorineural hearing loss. It is very uncommon to see bilateral otic capsule fractures but it would be an indication for cochlear implantation (17). After the fracture of the otic capsule, there would be intraluminal ossification or fibrosis which can make electrode insertion much more difficult. There should be preoperative imaging before surgery for providing additional information about fibrosis or ossification.

\section{Noise-induced hearing loss}

According to the World Health Organization (WHO), the number of people affected worldwide by hearing loss increased from 120 million to 250 million worldwide from 1995 to 2004 (18). Much of this impairment (16\%) may be caused by exposure to noise on the job (18). Noise induced hearing loss can be temporary or permanent. Acoustic trauma occurs after exposure to sounds louder than $140 \mathrm{~dB}$, such as sounds of gunshots or explosions. Outer hair cells are the most susceptible to noise exposure. After exposure to noise, the outer hair cells swell typically but if 
the noise exposure ceases, they may normalize. Most commonly a notch at $4000 \mathrm{~Hz}$ on pure-tone audiometry can be seen in the setting of hearing loss secondary to noise exposure, but hearing loss may advance to a degree and amplification can not provide good benefit then cochlear implantation may be considered (3).

\section{Tinnitus}

Tinnitus refers to abnormal perception of sound although there is actually no sound and it currently affects nearly $10 \%$ of the population (19). When tinnitus starts to reduce the quality of life, patients want to be cured and look for appropriate treatment. For patients experiencing severe tinnitus, tinnitus retraining therapy (TRT) is one of the proven treatment options. Because of its expense, limited number of programs, and duration of therapy, a significant number of patients with severe tinnitus leave TRT and remain without treatment (19).

In some studies it was reported that some patients with preoperative tinnitus which were CI recipients had informed either abolition or reduction of their tinnitus when they wore their CI $(20,21)$. In a recent study, patients with single-sided deafness were implanted for severe tinnitus and in 20 out of 21, tinnitus was reduced or ceased significantly. Three of the patients in this study even displayed constant residual inhibition while not wearing their processor. Up to date for severe tinnitus, cochlear implantation may be one of the most successful treatment options (20).

\section{Ménière disease}

Meniere disease is characterized by room spinning vertigo, aural fullness, tinnitus and fluctuating hearing loss. The diagnosis of this diease is made with a whole history and complete examination of the head and neck region, as well as imaging modalities to rule out retrocochlear pathology. Exact diagnosis can be made by examination of histology of temporal bones in subjects with Meniere disease and it reveals the dilation of the endolymphatic compartment. It is not clear whether endolymphatic hydrops is the final result of some other pathologic processes causing symptoms of Meniere or is the main reason for the symptoms.

House et al reported that in their study sample, in $11 \%$ of patients, Meniere's disease was bilateral at presentation and meanwhile an additional 12\% (14\% of unilaterals) became bilateral during the follow-up period (22). It is difficult to predict progression of hearing loss in Meniere but severe to profound sensorineural hearing loss may be a result. Recent studies on patients with Ménière disease underwent CI had overall better performance $(23,24)$.

\section{Presbyacusis}

With aging, hearing loss initially begins with high frequencies, than progresses to lower frequencies. Thirty to thirty five percent of 65 year olds have some hearing loss; this percentage rises to $40-50 \%$ for people over 70 years (25). Men are more commonly affected from presbycusis. Conventional hearing aids often supply benefit for patients, but only $20 \%$ wear this device. Patients with profound hearing loss who are unable to take advantage of traditional amplification may utilize from a CI (26). Sometimes some patients have residual low frequency hearing, and they may use hearing aid/CI combination providing both electrical and acoustic stimulation (27).

\section{CONTRAINDICATIONS}

Contraindications to cochlear implantation may include deafness because of lesions of eight cranial nevre or brain stem. They can be analyzed in two ways; relative and absolute. The absence of cochlear development demonstrated on CT and MRI as in Micheal deformity and cochlear atresia and lack of auditory nevre are some of the absolute contraindications. Several other absolute contraindications may be severe mental disease, severe mental retardation to cooperate with speech training and acute or chronic otitis media and mastoiditis without eradication of the disease $(2-4,6)$. Certain medical conditions like pulmonary, cardiac and hematologic conditions, uncontrolled epilepsy and not being available for rehabilitation remain relative contraindications. But secretory otitis media is not a surgical contraindication for cochlear implantation (Table 2).

Single-stage or more than one-staged surgery can be applied in chronic otitis media with tympanic membrane perforation (4). In single-stage surgery, any disease within the middle ear and mastoid cavity is eliminated by performing a myringoplasty and then the cochlear implantation is performed in the same procedure. More than one-staged surgery means firstly eliminating any disease, performing a 
Table 2. Contraindications for the cochlear implant

Contraendications for the Cochlear Implantation

\begin{tabular}{l|l}
\hline Absolute & \multicolumn{1}{c}{ Relative } \\
Agenesia of Cochlea & $\begin{array}{l}\text { Inappropiate medical conditions (e.g. pulmonary, } \\
\text { cardiac, hematologic) }\end{array}$ \\
Agenesia of Cochlear Nerve & Uncontrolled epilepsy \\
Severe mental disease & Not being available for postoperative rehabilitation
\end{tabular}

Acute/chronic otitis media and mastoiditis without eradication of the disease

Mental retardation to cooperate with speech training

myringoplasty or tympanoplasty and then performing the cochlear implantation 3-6 months later $(4,5)$.

\section{COMPLICATIONS OF THE SURGERY}

Complications of cochlear implantation are in a wide spectrum from temporary vertigo to death due to meningitis and related with medical, surgery or device problems (28). In literature, several forms of complication classification have been reported.

Kempf et al. classified the complications as early and late (29). They named the complications emerging in one week to 3 months - early complications and after 3 months - late (29). The complications of cochlear implantation were classified as major and minor by Summerfield and Marschall (Table 3 ) and they argued that minor complications can be healed with medical therapy without hospitalization but major complications may need hospitalization, revision surgery or reimplantation $(30,31)$.

Infections are the most common complications of the cochlear implantation. The frequency is between $7-16.6 \%$ (32). The most common causative organism in simple skin and wound infections is Staphylococcus aureus. It can be cured with oral antibiotic treatment without any need for hospitalization. Perioperative antibiotic prophylaxis may decrease the infection rates significantly.

Skin flap infections course is more serious and may need reimplantation. Hematoma may be a predisposing factor (33). Little insicions rather than bigger ones have decreased the insidence of all type of infections.

Pseudomonas infections can cause resistant infections around the implant and the possible reason for resistance is biofilm layer which decreased the penetrance of antibiotics and makes a barrier to immune mechanisms. Despite prolonged antibiotic therapy, reimplantation may be required (34).

Cholesteatoma is one of the late complications of cochlear implantation. During surgery, attention should be paid to protect the external auditory canal and especially bony tympanic annulus. Patients with persistant otorrhea after surgery should arouse suspicion for cholesteatoma (35).

Perilymph gusher can be seen during surgery as one of the intraoperative complications. It shows itself with leakage of cerebrospinal fluid to surgical field during cochleostomy. It is commonly seen in children with cochlear anomaly.

Facial nerve damage is rare. Intraoperative monitorization helps to protect the nerve. If not treated carefully, burr shaft can damage the nerve and temporary facial paresis occurs. Also chorda tympani can be damaged during surgery and deterioration may be observed in the sense of taste. Therefore, surgery must be performed with the rich irrigation (36).

Magnet or receiver may be dislodged secondary to minor head traumas. But also allergic reactions, new bone formation or infections may be the causes of displacement. According to some authors, placing the implant into the bone socket properly and suturation to the neighboring tissues can prevent the dislodging (37).

Because of some complications, reimplantation surgery should be performed (32). These are:

* Serious skin infection

* Device failure

* Serious device failure 
Table 3. Major and minor complications after cochlear implant surgery

\begin{tabular}{|c|c|}
\hline & Minor \\
\hline Cerebrospinal fluid fistula & Pain \\
\hline Device Failure & Simple skin infection \\
\hline $\begin{array}{l}\text { Displacement } \\
\text { of the electrote }\end{array}$ & Dizziness \\
\hline $\begin{array}{l}\text { Misplacement } \\
\text { of the electrote }\end{array}$ & İmbalance \\
\hline $\begin{array}{l}\text { Facial nerve paralysis } \\
\text { or damage }\end{array}$ & Temporary facial paresis \\
\hline Facial stimulation & Otitis media \\
\hline $\begin{array}{l}\text { Flap infection or hema- } \\
\text { toma }\end{array}$ & Hematoma on scalp \\
\hline Perilymph gusher & Tinnitus \\
\hline Rejection of the implant & Vertigo \\
\hline $\begin{array}{l}\text { Displacement of the } \\
\text { implant }\end{array}$ & Chorda tympani damage \\
\hline Mastoidit & Damage to the dura \\
\hline \multicolumn{2}{|l|}{ Menengitis } \\
\hline \multicolumn{2}{|l|}{$\begin{array}{l}\text { Retraction pockets or } \\
\text { cholesteatoma }\end{array}$} \\
\hline Subdural hematoma & \\
\hline
\end{tabular}

* Mild device failure

And some complications may need revision surgery but no need for reimplantation (32);

* Skin infection (for drainage or debridement)

* Cholesteatoma

* Displacement of the magnet

* Displacement of the receiver

* Displacement of the electrote or early recognition of wrong placement.

\section{CONCLUSION}

The purpose of this review article was to provide an overwiev on the etiologies of hearing loss circumvented with cochlear implantation and to provide a discussion on indications, contraindications and complications of CIs. A great number of changes occur and indications are loosened for candidacy for cochlear implantation. Generally, accompanying and satisfactory changes in surgical techniques have also been accompanied by. Together, this has improved the benefit and safety of cochlear implantation. Indications for, and the advances in design of cochlear implantation have been paired by improvements in surgical practices and decrease in complications. The improvements in safety and influences have further encouraged the use of these devices. To reduce the surgery-related complications, the patient should be carefully assessed preoperatively and surgeons without prior experience should not perform an operation themselves; they should work with a more experienced surgeon when performing their first implantation.

\section{REFERENCES}

1. Parisier SC, Chute P. Cochlear implants: indications and technology. Med Clin North Am. 1991;75(6):1267-76.

2. Sampaio AL, Araújo MF, Oliveira CA. New criteria of indication and selection of patients to cochlear implant. Int J Otolaryngol. 2011;2011:573968.

3. Lee KH, Roland PS, Kutz JW, Isaacson B. Medscape. Indications for cochlear implants. 2014 May 23

4. Chen Z, Yu D, Wu Y, Zhou H, Shi H, Yin S. Indications and common surgical approaches for cochlear implantation in China. ORL J Otorhinolaryngol Relat Spec. 2009;71(4):187-91

5. Basura GJ, Eapen R, Buchman CA. Bilateral cochlear implantation: current concepts, indications, and results. Laryngoscope. 2009 Dec;119(12):2395401.

6. Chang KW. Genetics of Hearing Loss-Nonsyndromic. Otolaryngol Clin North Am. 2015 Aug 11. pii: S0030-6665(15)00086-9 [Epub ahead of print]

7. http://ghr.nlm.nih.gov/

8. Tang HY, Fang P, Lin JW, Darilek S, Osborne BT, Haymond JA, et al. DNA sequence analysis and genotype-phenotype assessment in 71 patients with syndromic hearing loss or auditory neuropathy. BMJ Open. 2015;5(5):e007506.

9. Foulon I, Vleurinck L, Kerkhofs K, Gordts F. Hearing configuration in children with cCMV infection and proposal of a flow chart for hearing evaluation. Int J Audiol. 2015:1-6. [Epub ahead of print]

10. Hood LJ. Auditory Neuropathy/Dys-Synchrony Disorder: Diagnosis and Management. Otolaryngol Clin North Am. 2015 Aug 18. pii: S00306665(15)00087-0. [Epub ahead of print]

11. Ji F, Li J, Hong M, Chen A, Jiao Q, Sun L, et al. Determination of benefits of cochlear implantation in children with auditory neuropathy. PLoS One. 2015;10(5):e0127566. 
12. Kaga K. Auditory nerve disease and auditory neuropathy spectrum disorders. Auris Nasus Larynx. 2015 Jul 21. pii: S0385-8146(15)00166-2. [Epub ahead of print]

13. Khalid S, Qadir M, Salat MS. Spontaneous improvement in sensorineural hearing loss developed as a complication of neonatal hyperbilirubinemia. J Pak Med Assoc. 2015;65(9):1018-21

14. Reefhuis J, Honein MA, Whitney CG, Chamany S, Mann EA, Biernath KR, et al. Risk of bacterial meningitis in children with cochlear implants. $\mathrm{N}$ Engl J Med. 2003. 349(5):435-45.

15. Bloch SL, McKenna MJ, Adams J, Friis M. Labyrinthitis Ossificans: On the Mechanism of Perilabyrinthine Bone Remodeling. Ann Otol Rhinol Laryngol. 2015;124(8):649-54.

16. Abbas L, Rivolta MN. Aminoglycoside ototoxicity and hair cell ablation in the adult gerbil: A simple model to study hair cell loss and regeneration. Hear Res. 2015;325:12-26.

17. Vermeire K, Brokx JP, Dhooge I, Van de Heyning $\mathrm{PH}$. Cochlear implantation in posttraumatic bilateral temporal bone fracture. ORL J Otorhinolaryngol Relat Spec. 2012;74(1):52-6.

18. Nelson DI, Nelson RY, Concha-Barrientos M, Fingerhut M. The global burden of occupational noise-induced hearing loss. Am J Ind Med. 2005;48(6):446-58.

19. Eğilmez OK, Kalcıŏlu MT, Kökten N. Questionnaire methods used in the psychosomatic evaluation of tinnitus. Kulak Burun Bogaz Ihtis Derg. 2014;24(5):303-10.

20. Van De Heyning P, Vermeire K, Diehl M, Nopp P, Anderson I, De Ridder D. Incapacitating Unilateral Tinnitus in Single-Sided Deafness Treated by Cochlear Implantation. Annals of Otology, Rhinology \& Laryngology. 2008. 117:645 -52.

21. Vermeire K, Van de Heyning P. Binaural hearing after cochlear implantation in subjects with unilateral sensorineural deafness and tinnitus. Audiology Neurootology. 2008. 14:163-71.

22. House JW, Doherty JK, Fisher LM, Derebery MJ, Berliner KI. Meniere's disease: prevalence of contralateral ear involvement. Otol Neurotol. 2006 Apr. 27(3):355-61.

23. Mick P, Amoodi H, Arnoldner C, Shipp D, Friesen L, Lin V, et al. Cochlear implantation in patients with advanced Ménière's disease. Otol Neurotol. 2014;35(7):1172-8.

24. Samy RN, Houston L, Scott M, Choo DI, MeinzenDerr J. Cochlear implantation in patients with Meniere's disease. Cochlear Implants Int. 2015 Jul;16(4):208-12.
25. Yang CH, Schrepfer T, Schacht J. Age-related hearing impairment and the triad of acquired hearing loss. Front Cell Neurosci. 2015;9:276.

26. Rafferty A, Tapper L, Strachan D, Raine C. Cochlear implantation in older patients: outcomes and comparisons. Rev Laryngol Otol Rhinol (Bord). 2013;134(3):119-24.

27. Arehart KH, Souza PE, Muralimanohar RK, Miller CW. Effects of age on concurrent vowel perception in acoustic and simulated electroacoustic hearing. J Speech Lang Hear Res. 2011;54(1):190-210.

28. Kutlar G, Koyuncu M. Complications of Cochlear Implants and Reimplantation. Turkiye Klinikleri J E.N.T.-Special Topics. 2012;5(1):47-51.

29. Kempf HG, Stöver T, Lenarz T. Mastoiditis and acute otitis media in children with cochlear implants: recommendations for medical management. Ann Otol Rhinol Laryngol Suppl. 2000;185:25-7.

30. Summerfield AQ, Marshall DH. Medical. Surgical, and technical complications in cochlear implantation in the UK 1990-1994: Report by the Medical Research Council Institude of Hearing Research on the evaluation of the National Cochlear Implant Program. London, England: HMSO Books; 1995:191-198.

31. Dutt SN, Ray J, Hadjihannas E, Cooper H, Donaldson I, Proops DW. Medical and surgical complications of the second 100 adult cochlear implant patients in Birmingham. J Laryngol Otol. 2005;119(10):759-64.

32. Venail F, Sicard M, Piron JP, Levi A, Artieres F, Uziel A, et al. Reliability and complications of 500 consecutive cochlear implantations. Arch Otolaryngol Head Neck Surg. 2008;134(12):1276-81.

33. Brown KD, Connell SS, Balkany TJ, Eshraghi AE, Telischi FF, Angeli SA. Incidence and indications for revision cochlear implant surgery in adults and children. Laryngoscope. 2009;119(1):152-7.

34. Germiller JA, El-Kashlan HK, Shah UK. Chronic Pseudomonas infections of cochlear implants. Otol Neurotol. 2005;26(2):196-201.

35. Kaila R, Evans RA. Cochlear implant infection due to cholesteatoma. Cochlear Implants Int. 2005;6(3):141-6.

36. Bhatia K, Gibbin KP, Nikolopoulos TP, O’Donoghue GM. Surgical complications and their management in a series of 300 consecutive pediatric cochlear implantations. Otol Neurotol. 2004;25(5):730-9.

37. Roland JT Jr, Huang TC, Cohen NL. Revision cochlear implantation. Otolaryngol Clin North Am. 2006;39(4):833-9. 